\title{
EL DOCUMENTO NOTARIAL \\ EN LA LEGISLACIÓN FORAL DEL REINO DE ARAGÓN
}

\author{
Ángel Canellas López (†)
}

El segundo Congreso Internacional de Diplomática, celebrado en Friburgo (Suiza) en octubre de 1969, tuvo como tema central de sus comunicaciones el estudio del documento notarial, y, con el propósito de contribuir al mismo, se redactaron unas breves notas relativas a la postura del derecho foral aragonés en materia de documentación notarial. Han permanecido inéditas, pero las consideramos de interés, por lo que se ofrecen para su edición en esta Miscelánea, en homenaje al profesor Federico Udina, $\tan$ vinculado, como archivero y medievalista, a los estudios de Diplomática española.

Estas notas pretenden sólo sistematizar algunas normas esparcidas en las prescripciones de los Fueros y Observancias de Aragón, disposiciones legales de largo historial desde su cristalización en el corpus conocido por Compilación de Huesca de 1247, y su magnífica glosa redactada en los mismos años por Vidal de Canellas, hasta los últimos retoques introducidos por sucesivos fueros acordados en las cortes del reino de Aragón y que llegan hasta fines del siglo XVII.

Las referencias a estos textos legales serán citadas abreviadamente con las siguientes siglas: $\mathrm{F}=$ Fueros, observancias y actos de corte del reino de Aragón. Editan P. Savall y S. Penén, Zaragoza, 1866, 2 volúmenes; FA= Los Fueros de Aragón, según el manuscrito 458 de la Biblioteca Nacional de Madrid. Publicados por G. Tilander, Lund, 1937; VM = Vidal Mayor. Traduccion aragonesa de la obra «In Excelsis Dei Thesauris* de Vidal de Canellas. Editada por G. Tilander, Lund 1956.

Pero para valorar la aportación de la legislación aragonesa a la doctrina y práctica del documento notarial, parece oportuno exponer, en breve advertencia preliminar, la historia de esta legislación. Con anterioridad a la fecha clave de 1247 en que se promulgó la primera compilación territorial de los fueros aragoneses, en cortes celebradas por el rey Jaime I en la 
ciudad de Huesca, de acuerdo con una frase de Vidal de Canellas, principal inspirador de esta reforma «la scientia de los fueros non pudo ser sabida de los omnes complidamente por mingoa de escriptos, o a penas pudo ser sabida la scientia entro al tiempo d'este libro" (VM, III, 43, 28).

\section{Los fueros y observancias de Aragón}

Es bien conocida, en sus líneas generales, la génesis del derecho foral del reino de Aragón. Un fuero latino dado a Jaca por el Rey Sancho Ramírez en el año 1063, al ser fundada una ciudad para pobladores efran$\cos$ », será origen de una extensa familia de ulteriores reelaboraciones de sus preceptos, por obra de juristas anónimos aragoneses de la comarca de Jaca o de las tierras al sur de la sierra de Guara, que redactan sus trabajos en provenzal. A medida que progresa la reconquista, el carácter local de la compilación foral se altera: así, juristas oscenses, al parecer, adaptaron a las necesidades de su región y época los preceptos forales de Jaca, y lo mismo ocurrió en el valle del Ebro y en el Bajo Aragón, donde surgieron sobre la base del derecho jacetano otras compilaciones escritas en latin o en aragonés.

Llegado el siglo XII, la influencia romanista sistematizó estos fueros, y las cortes aragonesas celebradas en Huesca en 1247 compilaron en ocho libros la vieja tradición foral aragonesa.

El artífice principal de esta magna obra fue el jurisconsulto Vidal de Canellas, obispo de Huesca y pariente del rey, autor además de una autorizadísima glosa a la compilación de los fueros, conocida por el «Vidal Mayor». Pero la actividad legislativa de los aragoneses originó, en siglos sucesivos, leyes promulgadas en sus cortes privativas y que se agruparon en cuatro libros más, añadidos a los ocho primitivos de la compilación de 1247. Este paulatino aumento de leyes determinó a las cortes de Monzón de 1547 a revisar aquellos doce libros de fueros; se extractaron entonces del conjunto todos aquellos que ya no estaban en uso y con los vigentes se compilaron nueve libros, dejando los desusados en un apéndice. Con esta distribución fueron impresos en 1552; y en sucesivas ediciones fueron añadidos en nueve cuadernos todos los fueros que se dictaron en la segunda mitad del siglo XVI y durante el siglo XVII; el cambio de dinastía, en 1700, cerró la actividad legisladora de los aragoneses.

También interesan para estas notas algunas otras fuentes jurídicas, llamadas observancias, usos y costumbres del reino de Aragón, que se tenían en cuenta por los jueces en sus sentencias: se recopilaron en el año 1427 por orden del rey Alfonso V y dio cima a este trabajo el justicia de Aragón Martín Díez de Aux en 1437, ordenando también en nueve libros todas sus variadas prescripciones. 
Bien conocido es el proceso, común a todo el occidente europeo, por el que en el siglo XII surge un renacimiento del documento escrito: transformaciones económicas, corriente jurídica romanista e influencia de la norma canónica, estudio del derecho en las primeras universidades, apogeo de las administraciones, etc. son concausas del auge de los documentos. Y, partida de ambientes eclesiales, cunde por toda la sociedad la idea de que el documento es testimonio que sobrevive a sus autores e intervinientes.

La documentación engendrada por las relaciones jurídicas entre particulares adquiere valor especial al imponerse la doctrina canónica de la autenticidad: documentos hasta entonces carentes de valor si habían muerto sus testigos, mantienen su vigencia más allá de la vida de éstos, si una mano o un sello los garantiza: esta mano o sello adquirirá autenticidad en función de su notoriedad; y los jueces, en clara relación con el poder público y ciertas autoridades en la esfera de su jurisdicción, autentican documentos a instancia de parte, es decir, en negocios ajenos a su competencia.

La autenticidad, basada en estos elementos validatorios del signo manual o del sello, produce inmediatamente la necesidad de un procedimiento de verificación: al viejo sistema de consultar a los testigos supervivientes, se añade ahora el del cotejo de los signos y sellos. Y todos, desde el siglo XII, buscan la redacción de un documento tras pactar un negocio jurídico, aunque en principio no sea legalmente obligatoria la prueba por escrito de los contratos medievales. Los jueces, con potestad para extender documentos auténticos, comienzan a delegar esta función en notarios, escribas profesionales muy arraigados en Italia, que asumen así cierta jurisdicción graciosa y extienden documentos dotados de fe pública.

El auge de la documentación entre contratantes particulares, fomentará la profesionalización del notariado: los emolumentos que produce su trabajo y la importancia social de su actividad acrecen su significado, y toda autoridad con jurisdicción se aplica a crear notarios, palanca social y económica de importancia.

\section{Los notarios en los fueros de Aragón}

El notario, tal como se perfila en los fueros de Aragón de 1247, es un depositario de la fe pública, facultado para extender documentos que hagan prueba en los negocios jurídicos contenidos en éstos. Delegada en ellos la facultad de producir documentos auténticos, desde este momento todas las personas físicas y morales capaces de autenticar documentos pudieron crear notarios, incluidas las comunidades de judíos y musulmanes, muy importantes en la sociedad aragonesa medieval.

Los notarios nombrados por el rey gozan de una amplia jurisdicción, pues pueden extender su actividad a todo el territorio aragonés. Por ello, en 
su nombramiento se adoptan especiales garantías de competencia, consistentes en un examen previo hecho por el vicecanciller de Aragón o el regente de la cancillería real (F.= Felipe II, 1153). Los notarios nombrados por otras autoridades o corporaciones extienden su jurisdicción a la propia territorial de quien los designa. Por tanto, el notario de un lugar no puede extender documentos en otro lugar, bien entendido que en la montaña aragonesa, donde la unidad geográfica es el valle, el notario radicado en un valle puede testificar documentos en toda esta comarca natural.

Una incidencia especial en la práctica notarial aragonesa se planteaba por la coexistencia de tres comunidades religiosas: la cristiana, la judía y la musulmana, cuyos miembros podían contratar entre sí: la compilación foral de 1247 dispuso que en estos contratos mixtos entre gentes de distinta ley religiosa actuaría de notario uno de la religión del contratante que se obligaba o prometía; la índole especial de los préstamos resolvía la competencia notarial en favor de la ley del prestatario ( $\mathrm{F} .=$ Fueros en desuso. II, De fide instrumentorum. Y en 1300 Jaime II dispuso que el notario de todo contrato mixto fuera siempre crístíano, aunque en negocios con judíos obligados, éste, o un testigo judío en su defecto, debían suscribir con su nombre el documento.

La independencia del notario respecto de la autoridad que lo nombra es total: así, el notario viene obligado a extender documentos incluso contra el señor o el concejo de su lugar de residencia; la negativa supondría suspensión por un año de sus funciones y podría acarrear incluso la privación perpetua del oficio (F. = IV, De notarii, año 1300). Una cortapisa en tal independencia notarial fue dictada por Juan II en 1461, al declarar nulos los documentos otorgados en negocios superiores a quinientos sueldos y extendidos por notario de un señorío, si perjudicaba al municipio o a alguien que no fuera vasallo de tal señorío,

El notario debe yivir con suficiencia de su oficio. De donde las prescripciones forales sobre un número determinado de notarios: ya Jaime II, en 1300 , ordenó un número restringido en cada localidad a fin de garantizarles medios de vida suficientes; pero este número clausus no se debió observar, y en el último cuarto del siglo XVII, Carlos II refleja el panorama de esta cuestión en el año 1678: si en las ciudades no existe número determinado de notarías en contra de ordenanzas locales que prescriben ciertas plazas. llamadas «de caja», en los pueblos se autoriza la creación de un notario por cada cien vecinos, con un tope máximo de seis, salvo en lugares donde haya también tribunal eclesiástico en que puede añadirse una plaza más; todo esto sin perjuicio de los privilegios de Huesca y de Benabarre que contaban con un número fijo de notarías desde antiguo. 


\section{Creación de notarios}

Los aspirantes al oficio de la notaría han de reunir en Aragón ciertos requisitos personales: condición de seglares, edad mínima, aprendizaje garantizado del oficio. He aquí algunos datos sobre estas exigencias.

La condición de seglar la imponía ya la compilación foral de 1247. Y comentando Vidal de Canellas esta prohibición de la notaría a los clérigos ordenados, aclaraba que, sometidos los notarios a procesos de acusación por falsificación documental, la condición sacerdotal les hubiera dado una posición privilegiada en su defensa. Pero esta prohibición a los clérigos ordenados de ejercer la notaría no afectó, en 1247, a cuantos documentos se hubieran emitido anteriormente por tales clérigos en lugares carentes de notario $(F A=125$ y $120 ; \mathrm{VM}=43,69$ y 70 ). Desde 1247 , todo notario que reciba ordenes sacerdotales cesará en su notaría (FA.= II,120,2).

La edad mínima es prescripción moderna: Juan II, en Cortes de Calatayud de 1461, dispuso la de 20 años ( $\mathrm{F}=\mathrm{IV}$, De tabellionibus), y en el siglo XVI Carlos I la retrasó a los 22 años, si bien autorizaba a computar en esta edad los tres años de prácticas que entonces se exigían a los notarios en ciernes ( $\mathrm{F}$ := Carlos I, 1533); para evitar subterfugios, Felipe IV dispuso que se probase la edad del aspirante mediante acta pública de bautismo (F.= Felipe IV, año 1626).

En cuanto al aprendizaje del oficio, se exigía, y así lo dispone Juan II en 1461, practicar el arte notarial durante dos años, ya en escribanías de justicia, ya con un notario de ciudad o villa. Anteriormente, un fuero de 1300 sólo exigía que el notario fuera hombre de leyes y suficiente ( $F=I V$, De notarii). Los dos años de prácticas exigidas en la baja Edad Media aragonesa, aumentaron a tres en $1533(\mathrm{~F} .=\mathrm{Carlos} \mathrm{I}, 1533)$ y a cuatro en 1547 , de ellos dos con notario de caja y otros dos con escribano judicial (F.= IV, De notarii, 1547). Un fuero de Felipe IV, de 1626, precisa más el modo de realizar este aprendizaje práctico: para los dos años de prácticas con notario de caja, el pretendiente a notario deberá comer y dormir en casa de su maestro quien no podrá cobrar al pupilo más de treinta libras por año; y para la práctica en escribanía de justicia se puede frecuentar alguna oficina de la Real Audiencia de Zaragoza o del Justicia de Aragón o del zalmedina zaragozano; fuera de Zaragoza valen las prácticas en tribunal de lugar con voto en cortes o con más de cuatrocientos vecinos y que tenga, por supuesto, jurisdicción civil y criminal $\left(\mathrm{F}_{\mathrm{f}}=\right.$ Felipe IV, 1626).

Este aprendizaje se comprobaba mediante un examen: los examinadores habían de ser letrados (F.= IV, De notarii, 1300) que según la compilación de 1247 habían de ser dos, uno clérigo y otro seglar. El examen consistía en comprobar si el aspirante era capaz de redactar documentos (FA. = II, 120. 5); según prescripción del siglo XVII, se les examinaba también de latín (F.= Felipe IV, 1626). 
Ya en el siglo XVII, los fueros imponen algunas condiciones más a los notarios en ciernes: así, era necesario hacer una información de vida para comprobar su condición de cristianos viejos; no podían haber ejercido oficios mecánicos o tenido botiga y tienda abierta; debian además contar con patrimonio propio de al menos trescientas libras jaquesas. Y todos estos requisitos debían constar en el documento de creación (F.= IV, De tabellionibus, 1461).

Nombrado el notario, había de jurar su oficio sobre la Cruz y los Evangelios: su promesa hace alusión a la lealtad y veracidad para todos en el desempeño de su oficio (FA.= II, 120,5); de ahí la nomenclatura de escribano jurado con que suele designarse.

\section{El arancel notarial}

Los notarios vivían de los salarios percibidos de la clientela. Estos salarios estaban fijados por el fuero y no podían percibirse hasta que el notario hubiera escrito in extenso el documento solicitado $\left(\mathrm{F}_{1}=\mathrm{IV}, \mathrm{De}\right.$ salariis notariorum, 1461 y 1495).

Los fueros se cuidaron de dictar aranceles para cada uno de los contratos: los referentes a matrimonios pagan de arancel entre 8 y 50 sueldos en función del importe de los bienes constituidos como dote matrimonial, en una escala desde importes inferiores a los 1.000 sueldos hasta los excedentes de 20.000 sueldos jaqueses (F.= Fueros en desuso, XI, De taxatione scripturarum). Los actos de última voluntad (testamentos, codicilos, donationes mortis causa, etc.), los inventarios y las donaciones inter vivos, se ajustaban en general al arancel previsto para las compraventas; éstas, al igual que los arrendamientos, las comandas y las deudas, cotizaban de 10 a 100 sueldos, en escala proporcional al importe del negocio, precio, préstamo, etc., desde cantidades inferiores a los 1.000 sueldos hasta los excedentes de los 9.000 jaqueses. A esta tarifa se añadía, para arancel de los recibos engendrados por el contrato principal, una tasa equivalente al tercio de la abonada por éste ( $\mathrm{F} .=$ Fueros en desuso, De tabellionibus, 1436).

Los treudos (nombre aragonés de las pensiones anuales enfitéuticas), tanto perpetuos como los temporales por menos de cuarenta años, con comiso, loismo (redención) y fadiga (derecho del señor directo en las enajenaciones), abonaban también arancel al notario en cuantía variable desde 10 a 100 sueldos jaqueses, en proporción al importe de la renta anual, desde menos de 10 a más de 500 sueldos (F.= IX, De taxatione scripturarum, 1442). Un arancel semejante se cobraba en la constitución de censales y de violarios (pensión que se asegura a uno por toda su vida, mediante la cesión que éste hace de su hacienda o parte de ella) (F.= IX, De taxatione scripturarum, 1442; Fueros en desuso, XI). 
Los albaranes (recibos) muy frecuentes en la contratación, pagan un arancel muy modesto, que oscila entre 8 dineros por recibos inferiores a 50 sueldos y 1 sueldo por cada millar, sin jamás sobrepasar los 50 sueldos $(\mathrm{F},=\mathrm{IX}$, De taxatione scripturarum, 1442). Finalmente, los arbitrajes o compromisos abonan por arancel notarial la cantidad fijada por los árbitros o, en su defecto, por el juez, pero en todo caso no puede ser superior a los 100 sueldos jaqueses $(\mathrm{F} .=$ IX, De taxatione scripturarum, 1442).

Las segundas expediciones de documentos abonan sólo la mitad del arancel principal previsto para el original $(\mathrm{F} .=\mathrm{IX}$, De taxatione scripturarum, 1442); y las dietas por desplazamientos del notario fuera de su residencia se evalúan en 7 sueldos diarios $(\mathrm{F}$. $=$ Fueros en desuso, $\mathrm{XI}, \mathrm{De}$ taxatione scripturarum).

La documentación motivada por la administración de justicia cuenta con un arancel especial. Si se trata de documentos destinados a un individuo abonan por pieza 5 sueldos y 2 dineros, $y$ si se trata de una colectividad, 12 sueldos y 2 dineros. Los documentos judiciales se prestan a abusos arancelarios y por ello son frecuentes los fueros restrictivos sobre sus tasas: en 1390 Juan I disponía de la tasa de 8 dineros por pieza en documentación original y 3 en las copias. El término pieza se entiende en su valor codicológico de cuademillo, generalmente un cuaternión de 16 páginas; para evitar abusos el mismo rey disponía que la plana de estas piezas debería llevar 20 renglones como disponían los antiguos fueros del reino $(\mathrm{F}=\mathrm{IV}$, De taxatione scripturarum, 1390). En 1461, el rey Juan II reiteró la tasa de los 8 dineros por pieza o cuadernillo del proceso y los 20 renglones por plana o página: no valía arguiir que la escritura era espesa y por ello debía cobrarse más (F.= IV, De tabellionibus, 1461). Carlos I elevó la tasa por pieza o cuadernillo grueso a 16 dineros: se trataba de cuadernillos dobles compuestos por 32 páginas; dispuso además que cada página llevaría 25 renglones $(\mathrm{F}$. = Carlos I, 1533). Y en el siglo XVII, para aminorar los gastos a los litigantes, Carlos II dispuso que en planas donde figurasen declaraciones de testigos, irían 20 renglones por página y que el juez podría aminorar el arancel si faltaban renglones o estaban escritos con tal calidad que los trazos se habían ensanchado o alargado con arte o malicia a fin de aumentar la extensión de la copia (F.=Carlos II, 1678).

\section{Los protocolos notariales}

La fe notarial afirmada en la supervivencia de los escritos auténticos a sus autores, testigos y rogatorios se apoya en la confección de protocolos, es decir, registros en los que se insinúan todas las actuaciones del notario. La nota del protocolo es un verdadero documento original, aceptado en el procedimiento judicial y en el comercio habitual de las personas. Una vieja observancia del reino de Aragón ya anotaba que las nótulas verdaderas 
daban validez a los documentos de los que quedase copia viciada por raspadura o cualquiera otra alteración $(\mathrm{F} .=$ Observancias, II, De fide instrumentorum).

Por ello los notarios debian trasladar a sus protocolos los documentos, en principio por su propia mano y antes de transcurrir seis meses desde la celebración del negocio jurídico documentado. Esta insinuación en el protocolo estuvo sometida a ciertas garantías; Pedro IV, muy meticuloso en estos asuntos, disponía en 1348 que los notarios insinuaran los documentos completos, en su integridad, sin abreviaturas ni obscuridad de signos, so pena de perder el notario su oficio. Como esto a veces resultaba muy trabajoso, se autorizó a que tras un contrato se insinuaran en el protocolo otros de la misma naturaleza jurídica oportunamente abreviados en sus fórmulas contractuales, sin alteración de su sustancia y copiando íntegramente aquellas partes, especialmente en el texto dispositivo, que eran peculiares de cada contrato ( $\mathrm{F} .=\mathrm{IV}$, De tabellionibus, 1349).

Los documentos insinuados en los protocolos podian ser en todo momento extendidos en copia auténtica, o gruesa (grossa littera) a petición de los interesados. Lo natural era que realizara este menester el notario autorizante, autor de la nota protocolizada; pero en defecto suyo, sobre todo tras su fallecimiento, otro notario poseedor de su protocolo podría poner en forma pública la nota protocolizada, siempre que no hubiera sospecha sobre la legitimidad de aquellas notas; en la suscripción notarial de esta copia auténtica habría que aludir a todas estas circunstancias $(\mathrm{FA}=125$ y 120 ; $\mathrm{VM}=\mathrm{III}, 43,51$ a 54 ). La utilización de notas ajenas por otro notario obligaba a éste a expresar en la copia auténtica el negocio tal como lo redactó el predecesor: no son admisibles innovaciones a cargo del segundo notario, que se limita a extender la copia de lo recibido $(\mathrm{F}=$ Observancias, II, De fide instrumentorum, 12).

Nótese, desde el punto de vista de consulta de los protocolos notariales de Aragón, la frecuencia de cancelaciones mediante un rayado de renglones, o mediante aspas que cruzan toda la página cancelada; tales formas cancelatorias tienen valor distinto, pues la primera - tachado de cada renglón - indica que aquel contrato fue anulado por los contratantes, y la segunda - cancelación por aspas - alude a que de aquella nota el notario ha extractado ya una copia auténtica (VM. $=$ III, 45, 14-5).

Dado pues el valor de las notas protocolizadas, los fueros han regulado cuidadosamente la conservación y destino de las mismas. Así, las notas siempre deben permanecer en el lugar de origen y en principio siempre en poder de notario. Los protocolos que al fallecer deja un notario constituyen una fuente de ingresos importante, pues a ellos han de recurrir los interesados en extractos y copias de contratos, previo pago del arancel oportuno. Así, siendo los protocolos un auténtico capital con su renta en potencia, deben ser heredados por los familiares del notario difunto: si hubiera un 
hijo, nieto o yerno de oficio notario, no se plantea problema alguno, pues recaen en la misma persona los derechos sucesorios y la garantía profesional de la fe pública: entonces el juez encomienda los protocolos de oficio a cualquiera de estos herederos. Pero en ausencia de éstos hay que entregarlos a otro notario, en principio residente en el mismo lugar del fallecido, $o$ en su defecto en una localidad inmediata; los herederos naturales del notario fallecido percibirán en su caso parte de los aranceles cobrados por copias extractadas de aquellos protocolos.

Para garantía de la custodia y destino de los protocolos, la autoridad recoge estas notas en la casa del difunto y las conserva hasta que en el plazo de diez días las deposita en poder de quien extenderá copias. Felipe II aclaraba, en 1592, que una de las razones de tanta precaución era evitar que cayeran los protocolos en poder de familiares femeninos del notario difunto, pues generalmente desconocían el valor y trascendencia de aquéllos (F.= Felipe II, 1592).

Si no existiera en la familia del notario difunto persona de esta profesión, el de cuius puede dejarlos en testamento a quien desee, a condición de que no salgan del lugar en que se elaboraron; si el heredero carece del oficio de notario, pondrá los protocolos heredados en manos de quien lo sea, ya del lugar, ya de poblado próximo. Caso especial fue la sucesión en protocolos notariales de Zaragoza; en tiempos de Carlos II un fuero recordaba que en esta capital del reino de Aragón los protocolos de notario carente de sucesor notario en su familia debían depositarse en el Monasterio jerónimo de Santa Engracia, cuyo escribano principal se constitúa en depositario de las notas. Del arancel cobrado por extractas y copias, había de dar la mitad a los herederos del difunto y êl se reservaba la otra mitad; si no hubiera heredero, el monasterio depositario percibía esta mitad del arancel (F.= Carlos II, 1678).

\section{Formalidades del documento notarial}

Los fueros aragoneses aluden a varias formalidades externas e internas del documento notarial. Unas afectan a su soporte, a su escritura, a su presentación y a sus posibles irregularidades; otras se refieren a su tenor diplomático, en el que han de constar determinadas cláusulas so pena de nulidad y ciertos elementos autenticantes como son las suscripciones de los contratantes y del notario, más los signos y sellos validatorios.

La compilación de 1247 recomendaba el empleo de pergamino para la extensión de documentos notariales, con preferencia a tabletas enceradas y a papel, soportes citados en aquella fuente legal (FA. $=125$ y 120; VM= 43, 65). En cuanto a la escritura, los notarios tenían obligación de escribir el documento de su propia mano: en 1646 ya se admitía oficialmente una costumbre muy antigua, la autografía notarial de los dos prime- 
ros renglones del documento inserto en el protocolo, y de los renglones donde se estampase la data y los nombres de los testigos ( $\mathrm{F}=$ = Felipe IV, 1646).

Causa de estas prescripciones fue la costumbre de algunos notarios, especialmente los de mucha clientela, de delegar en sus discípulos o aprendices la extensión por escrito de los documentos. Admitida esta práctica, los fueros del siglo XIII ya dispusieron que tales discípulos deberían colocar suscripciones indicando claramente el nombre del notario en nombre del cual extendían el documento, entendiendo por claramente la consignación de nombre, sobrenombre y oficio con todas sus letras, sin abreviatura alguna. Lo que no evitaba que el notario titular suscribiera también y señalase en este lugar el nombre y circunstancias personales del discípulo escribiente. Pero esta lasitud no impedía una recomendación expresa del fuero en el sentido de que fuera el notario con preferencia al discípulo quien escribiera el documento (FA. $=125$ y $120 ; \mathrm{VM} .=\mathrm{III}, 43$ ).

La escritura de los documentos debía evitar las abreviaturas, sobre todo en las menciones de nombres de personas, cantidades de dinero, número de objetos, fecha del día y del año: para estos datos se prescribía la expresión de cifras mediante las palabras enteras.

Era también importante la presentación cuidada: sobrepuestos, raspaduras e interlineados debían ser cuidadosamente salvados. Los sobrepuestos se salvaban de puño y letra del notario, concediéndole seis días de plazo para tales salvedades en la parte en blanco de aquella página en donde figuraba el sobrepuesto (F.= Felipe II, 1585). En cuanto a las raspaduras, si eran de poca monta o iban al principio o en lugar de formulario donde para nada afectaban la sustancia del negocio, o se trataba de un simple hermoseamiento, o incidian en lugar donde a nadie favorecían o perjudicaban, o simplemente nada tenían que ver con la veracidad del asunto, en cualquiera de estos casos, tales raspaduras podían pasarse por alto. Pero si suponían daño para alguien, afectaban al nombre de los objetos del contrato o de las personas, a la calidad o cantidad de las cosas, a la promesa o condición contractual, a la fecha en sus elementos cronologicos, en cualquiera de estos casos, el documento se viciaba de falsedad (FA. $=125$ y 120 ; $\mathrm{VM}=43$ ). Entonces el notario había de hacer alusión a estas raspaduras en la suscripción indicando dónde estaban y qué es lo que debían expresar.

Los interlineados tenían un tratamiento parecido al de las raspaduras: el escribano o notario los refería en suscripción autógrafa, con lo que el documento se reputaba por legítimo; en esta salvedad de la suscripción se había de aludir a los renglones a que afectaba el ínterlineado (FA. $=125$ y 120; VM $=$ III, 43). Estas salvedades sobre los sobrepuestos, las raspaduras y los interlineados fueron ampliamente reguladas en el siglo XVII. La antigua recomendación de los fueros del siglo XIII, que señalaban al notario forzado a raspaduras e interlineados en lugar sospechoso la conveniencia de 
volver a escribir un nuevo documento (VM= III, 43), ahora se completa - de no hacerse este nuevo documento- con la orden al notario de salvar todo ello de su propia mano al final del documento, escribiendo además las palabras inmediatas precedente y siguiente a la enmienda, raspadura o interlineado. Además, en las notas de los protocolos, debía poner el notario, al final de cada documento, la declaración de no existir estas anomalías, o si existían, en qué consistían ( $\mathrm{F}$ = = Felipe IV, 1626).

\section{Particularidades de algunos documentos notariales}

En los fueros de Aragón figuran incidentalmente algunas particularidades de ciertos documentos notariales, en donde se reflejan a su vez la naturaleza y contenido de determinadas obligaciones y contratos. Era preceptiva, según el fuero, la intervención notarial en la extensión de documentos relativos a toda clase de negocios civiles: donaciones, compraventas, arrendamientos, préstamos, testamentos, etc. También era abundante la documentación intervenida por el notario en el campo procesal.

La donación exige documento ante notario, en el que figure firme o fiador de salvedad y testigos, cuyos nombres constarán claramente en el documento; en otro caso, la donación quedaría invalidada por vicio formal (FA. = II,126; VM. = III, 44, 2). Sólo escapan a la necesidad de firme o fiador de salvedad la donación del rey y de persona religiosa; en realidad es suficiente garantía de legitimidad en tales casos la presencia del sello del donante o su suscripción (FA. $=$ II, 126; VM. $=$ III, 44, 3).

Las compraventas de inmuebles exigen señalar claramente en el documento el nombre del lugar en cuyo término se halla situada la finca, más los linderos de ésta, ya por todas sus partes, ya al menos por dos de ellas $(\mathrm{FA} .=\mathrm{II}, 126 ; \mathrm{VM}=\mathrm{V}, 25,2)$; pero no hay que indicar los linderos si se trata de castillos, torres, baños, hornos y molinos, en los que frecuentemente coinciden copartícipes en su propiedad (VM $=$ III, 44, 5). En tales casos el fuero preceptúa una fórmula para enajenar, que es ésta: «Yo tal, vendo, do, empenyo a tí tal, o traspaso, que sea de tu dreyto o tu sennorio por tal razón, por tal cantidat de precio, la meatad o la tercera parte o la cuarta o cualsequiere otra parte que pertaynesce a mí en tal cosas (FA.= 172; $\mathrm{VM}=36,3$ ).

Los arrendamientos verificados con documento notarial tienen una fuerza especial y no pueden ser deshechos (VM. $=I, 56,48)$.

Los préstamos o manleutas han de consignarse por escrito (FA.= I, 72, 1). Las deudas hay que extenderlas en documento público (FA. $=\mathrm{I}, 64$, 1), de ahí la importancia concedida en el derecho procesal aragonés a la recuperación del documento de deuda $(\mathrm{VM},=\mathbf{I}, 11)$ y la exigencia de fiadores y testigos en documentos de préstamos (VM=I, 8). Y para todas las 
obligaciones de las que dimane un pago está previsto el documento recibo, llamado en aragonés albarán. De tales cartas de pago o recibo hay muchas citas en los fueros (FA. = II, 124, 1) y se cuida de ordenar que las redacten notarios cristianos en contratos mixtos con judíos o musulmanes, a fin de evitar malicias y engaños.

El testamento o carta de destín, la confecciona el notario, recibiendo la voluntad del testador en presencia de testigos $(\mathrm{FA}=\mathrm{V}, 232)$. En este documento es obligado mencionar los nombres de cabezaleros y de testigos, pues son parte importante para la comprobación del documento $(\mathrm{FA} .=$ II, 126). Prevé el fuero la extensión de testamentos por escrito sin intervención notarial, pero, en este caso, para dar legalidad al mismo, dos al menos de los testigos y cabezaleros habrán de concurrir a la puerta de la iglesia que frecuentaba el testador y jurarán ante notario que aquélla es la voluntad del difunto $(F A=V, 232)$. En caso de testamento oral, los espondaleros o cabezaleros, o al menos dos de ellos, convocarán a un notario ante el justicia, donde dictarán la voluntad del muerto, firmando con juramento que ésa era la verdad (FA. $=V, 231)$.

Está prevista en el fuero la posibilidad de otorgar testamento ante clérigo, pero no pasaría tal documento de pura preparación; es preciso que tal escrito lo adveren sus testigos ante un notario, quien lo eleva al rango de documento auténtico (FA. $=125$ y 120; VM.= III, 43, 71, 7).

Los documentos de áltima voluntad interesan a todos los afectados por la voluntad del testador; de ahí que los fueros adviertan la necesidad a los notarios de entregar copias auténticas del testamento a todos los herederos y legatarios, copia que se basará en el documento o nota original protocolizada $(\mathrm{VM}=\mathrm{I}, 58,30)$, aunque en realidad baste con trasladar a cada interesado aquella cláusula de su particular interés (VM.=I, 58, 26).

La documentación judicial, engendrada por los procesos, es abundante y variada: citaciones, demandas, excepciones, responsiones, etc. son las formas más frecuentes (VM $=I I, 4,37$ ); por supuesto la más importante es la sentencia. Importan también los documentos de procura para litigar, que han de extenderse ante notario o mediante declaración ante el juez (VM.=I, 43,2 y 4). En el proceso, las declaraciones de testigos, muy frecuentes, se toman por escrito ante notario judicial (FA.= II, 115). También exigen constancia escrita las citaciones, que una vez formuladas no ha lugar a deshacer $(\mathrm{VM}=\mathrm{I}, 12,9)$.

Las sentencias, siempre dadas por escrito (VM.= II, 4), engendran copias para cada uno de los litigantes; por lo general van autenticadas con el sello del juez, pero también vale como garantía una copia notarial $(V M=$ VI, 29, 10-15). En las sentencias han de figurar los testigos que asistieron al pronunciamiento (VM. $=\mathrm{II}, 4,35)$. 


\section{Valor del documento notarial}

En los fueros de Aragón se presenta el documento como muestra y defensa de los derechos (FA. =I, 54,1). Las citas sobre el valor probatorio del documento son frecuentes: aducir cartas, supone, en lenguaje foral aragonés, enfortecer el derecho de uno (FA. $=\mathrm{I}, 64 ; \mathrm{VM}=\mathrm{I}, 58,22)$, y un documento sólo puede ser combatido por otro $(F A=I, 48 ; V M=I, 50,18)$. Aún se perfila más la fuerza probatoria del documento escrito en algunos textos recogidos por las observancias; el juez ha de juzgar conforme a lo que diga su texto, se ha de respetar lo que contenga salvo si fuere algo contra el derecho natural o algo imposible y si en el mismo documento hubiera pacto de otra cosa (F.= Observancias, II, De fide instrumentorum, 16).

Este valor probatorio del documento afecta por supuesto al extendido por notario: así no vale el documento hecho por quien no tiene esta condición de escribano jurado (VM.=III, 40), por lo que los documentos privados sólo hacen fe en juicio si se trata de negocios de sociedades mercantiles para los que la ley aragonesa medieval consideraba suficiente prueba la de la contabilidad y los escritos privados $(\mathrm{F} .=$ Observancias, II, De fide instrumentorum, 10).

La necesidad de documento notarial para prueba en juicio de los derechos plantea la casuística de personas que aduzcan como defensa que el notario del documento en cuestión no era tal; hay entonces un procedimiento judicial consistente en que el juez llama a hombres buenos del lugar en que aquel escribano actuaba a fin de que juren si fue o no notario público; y basta su juramento afirmativo para tener por auténtico aquel documento (FA.= II, 122; VM.= III, 41, 33).

Hay otras circunstancias materiales que afectan al valor del documento; así, se exige la integridad física del documento, que carezca de roturas, cancelaciones o cualquier empeoramiento (VM: $=\mathrm{III}, 37,5)$. Uno de estos empeoramientos es la clásica cancelación mediante cortes con que se anulaba un documento ya inútil; era cómodo expediente en documentos acreditativos de deudas hallarlo cortado en poder del deudor, pero según observancia aragonesa, tal documento ya no admitía reparación, aunque el acreedor jurase que se lo habían robado $(\mathrm{F}=$ Observancias, II, De fide instrumentorum, 9). Las cartas partidas, expediente diplomático usado con frecuencia para la consignación de deudas, sólo servían para reclamar lo debido si las presentaba el interesado o su procurador $(\mathrm{F}=$ = Observancias, II, De fide instrumentorum, 17).

Muy distinta es la casuística del documento tenido por sospechoso. Unas veces se trata de piezas en las que se ha dado apariencia de antigüedad mediante recursos variados, tal como la cita de nombres de gentes que murieron hace tiempo, tal el teñir la superficie del soporte documental a fin de darle apariencia de vejez, tal algunos cambios sospechosos en la escritu- 
ra empleada, etc. Los fueros de Aragón recogen algunas ligeras nociones de crítica diplomática; así, en el caso de documentos con falsa apariencia de vejez, se previene el posible empleo de humo que amarilleó artificialmente la superficie; la superchería se descubre además por haber olvidado imitar una escritura antigua conforme a la época que se desea aparentar, o por una tersura $e$ integridad del pergamino impropia de su aparente vetustez.

También hay indicios de sospecha si se examinan los contenidos del documento: las palabras inadecuadas, las expresiones insuficientes para crear una obligación - como omitir el nombre del obligado-, el olvido en consignar las lindes de las heredades o la fecha de algún documento citado en el contrato, etc. son los más frecuentes (F = IV, De tabellionibus, 1349; $\mathrm{FA} .=\mathrm{II}, 122 ; \mathrm{VM}=44,41$ ). Pero si el vicio del documento radica en alguna cláusula que aparece incompleta, solamente se tendrá por inválida tal cláusula, y será valedero el documento en todo lo demás $(\mathrm{F}=\mathrm{IV}, \mathrm{De}$ tabellionibus, 1436).

Grado distinto de invalidez ofrece el documento falso, es decir, el escrito falsamente a sabiendas. Los fueros abundan en citas numerosas de falsedad documental; unas veces, sobre un documento legítimo y auténtico, se han introducido pequeños retoques en alguna letra, lo que suele descubrirse por un cambio de tinta y color (FA. $=125$ y 120 ; VM.=III, 43); otras veces la falsificación es más burda, y sobre un documento legítimo se encola una pieza nueva donde se escribe algo alterado; el fuero previene una inspección ocular al trasluz para descubrir tal superchería $(\mathrm{FA}=125$ y 120; VM.= III, 43).

Hay otras falsedades internas: son esos documentos que el notario redacta en forma distinta a cómo proponían las partes, o donde se alteran cantidades, objetos, términos, condiciones, etc. o donde se consignan fiadores que no lo fueron o nombres de testigos que no aceptaron su misión o no estuvieron presentes en la confección del documento; o se trata de cambios en la fecha, o cita de un notario que en realidad no intervino en la documentación (amplia casuística en FA. $=122$ y VM: $=I I I, 41,5$ a 11 ).

Para la declaración de falsedad del documento es preciso ante todo una denuncia. El denunciante viene obligado entonces a decir ante el juez el porqué de esta falsedad, o en otro caso el juez lo exigirá de oficio (VM.= III, 41). Denunciado un documento como falso, el juez lo retiene y se abre un plazo de año y día para que el denunciante pruebe su aseveración, con los correspondientes plazos para la comparecencia de testigos, notarios, etc. traídos a la prueba. Si en año y día no se demuestra la legitimidad del documento, éste queda por falso y quien lo adujo sufrirá pena pecuniaria de 60 sueldos jaqueses. Solamente el rey puede conceder prórroga al plazo de año y đ́́ ( $\mathrm{FA} .=125$ y 120 ; VM.=43), y se suele fundar en la condición de los testigos, la lejanía de sus residencias, pertenecer a jurisdicciones ajenas a la del juez que instruye la causa, etc. 
Los documentos tenidos por falsos abren causa ante el juez y a ella concurren las partes interesadas en el negocio documentado, o al menos una de ellas si la otra se manifiesta ausente contumaz. El procedimiento consistía en la lectura pública del documento puesto en tela de juicio en presencia de los testigos en él citados más del notario que en su día lo cerró; seguidamente se daban a conocer las razones por las que se pretendía declarar su falsedad.

Estos testigos y notario supervivientes son llamados, pues, a la adveración del documento denunciado. Los testigos deben declarar conforme a esta fórmula: «Yo tal, testigo, fu presente ad aqueillas cosas que en est instrument son leydas.» Al notario autor del documento, el juez preguntará si reconoce por suyo aquel documento, cuya declaración ha de venir avalada por la de otros notarios vecinos del declarante: si éstos declaran ser documento de aquel notario, a éste se admite en seguida para que preste la siguiente jura, que dará la validez al documento en juicio: «Yo tal, juro por estos santos Evange lios que est instrument que agora est leydo en juditio est verdadero, et asy fue mandado que fuese feyton; esta frase la pronuncia de rodillas ante el juez con la mano sobre cruz y evangelios, $y$ suele añadir « $E t$ yo como escribano fu present en eillo et escreví todo aqueillo que aqueill instrument dice» $(\mathrm{VM},=\mathrm{III}, 41,12-15)$. Hay otra fórmula para el juramento de notario y de testigos en las observancias aragonesas: «Nosotros tales, juramos por Dios y estos santos Evangelios que tal se obligó y prometió a tal tal cosa, tal como se lee en el documento; $y$ mandó que se hiciera todo lo que en él se contiene; $y$ dicho instrumento en todo y por todo contiene la verdats $(\mathrm{F} .=$ Observancias, II, De fide instrumentorum, 1$)$.

Si un testigo advera el documento y otro no, aunque el notario citado lo advere, no se admitirá por verdadero, a no ser que otros testigos que no se consignan en el documento pero que asistieron a su confección, aseguren la veracidad del mismo (F=Observancias, II, De fide instrumentorum, 7). Otra casuística es la de ciertos documentos no adverados en alguna de sus cláusulas; en éstas se reputarán por falsos pero el resto se tendrá por verdadero ( $\mathrm{F} .=\mathrm{IV}$, De adveratione instrumentorum, 1442).

El notario y los testigos solicitados pueden negarse a jurar; en tal caso el juez les conminaría a jurar al menos sobre la veracidad de haber asistido al acto en que se confeccionó el documento; y caso de una declaración afirmativa, el juez puede obligarles a dar juramento sobre la veracidad de lo contenido en el instrumento (FA. = 122; VM.= III, 41, 19).

Pero la vida introduce casuísticas en este sistema de adveración, pues no siempre viven los testigos y el notario: las combinaciones de supervivencia son varias, $y$ en cualquier caso el superviviente viene obligado a jurar ante el juez con fórmulas análogas a las citadas (FA.= II, 122; VM.=III, 41, 16); pero muertos el escribano y los testigos, la parte que aduce el documento 
puede probarlo por otro procedimiento. Es el viejo sistema de la contropatio, bien conocido en España en las fórmulas visigóticas del siglo VII. Se pueden presentar varios documentos extendidos por el notario fallecido en forma pública y en los que conste la identidad de escritura autógrafa del mismo (FA. = II, 122 y VM.= III, 41, 21); el fuero advierte sólo una prevención y es la de no admitir en cotejo documentos notariales traídos del archivo de aquel demandante que pretende probar la veracidad del documento dudoso $(\mathrm{FA}=122 ; \mathrm{VM}=\mathrm{III}, 41,23)$. Se trata, pues, de buscar la identidad de escrituras entre el documento en juicio y los aducidos: este cotejo puede ser negativo, pero aún se da otra oportunidad al demandado para que a su vez traiga documentos del notario difunto, sacados de archivo ajeno, para verificar un segundo cotejo (VM.=III, 41, 25-26).

\section{La « reparatio scripturarum»}

La pérdida de documentos en época de auge de la prueba documental es grave. Los fueros recuerdan los clásicos sistemas que ahora, con la organización notarial y las colecciones de notas protocolizadas, parecen muy simplificados. La pérdida de documento se formula a instancia de la parte perjudicada: ésta solicita del juez que convoque al notario rogatorio del contrato documentado a fin de declarar si hizo nota de tal negocio y si la conserva. Puede darse el caso de un notario que actúa con dolo y niegue conservar tal nota: el riesgo es grave, pues si se descubre su engaño, además de rehacer el documento perdido pagará daños ocasionados, multa de sesenta sueldos y perderá su oficio (VM.= III, 45, 2-6). También puede asegurar el notario que perdió la nota por fuerza mayor (incendio, avenida de agua, hurto, etc.), en cuyo caso, declarada esta circunstancia con juramento, puede proceder a rehacer el documento perdido $(\mathrm{VM}=\mathrm{III}, 45,11)$. Si el notario niega poseer la nota sobre tal documento perdido, dos hombres buenos acompañados de oficiales del juez pueden visitar su despacho, consultar sus protocolos y comprobar la certeza de lo declarado; si se hallase nota del documento reclamado, ésta se mostrará en público y el notario perderá oficio y abonará las penas mentadas (VM. = III, 45, 7-10).

Si hubiera fallecido el notario que tomó nota del documento perdido, el juez demandará de oficio las notas que dejó y, hallada la del documento en cuestión, siempre que aparezca en lugar no sospechoso, se procederá a rehacer el documento perdido por otro notario, de acuerdo con la nota hallada $(\mathrm{VM}$ = III, 45, 17-18). Muerto el notario y fracasado el hallazgo de sus notas, si el que perdió documento se halla en posesión pacífica de lo justificado por el documento perdido, el pregonero dará a conocer en el lugar lo sucedido y tras juramento del que perdió el documento, se le hará otro por el notario $(\mathrm{VM}=\mathrm{III}, 45,19-21)$. Hay un caso en que no puede rehacerse el documento perdido: si aludía a deudas o a la posesión de bienes 
muebles, en cuyo caso, muerto el notario autorizante y desaparecidas sus notas, no hay posibilidad legal alguna de rehacer el documento $(\mathrm{VM}=\mathrm{III}$, 45,22 ).

En el manuscrito Perrins, donde se transcribe el Vidal Mayor, en el folio 125 hay una miniatura adornando una letrina inicial, donde figura representada la escena de la ureparatio scripturarum»: un escribano jura, un juez pide el juramento, asiste el interesado en rehacer el documento y le acompaña un testigo. 